NBER WORKING PAPER SERIES

\title{
CORPORATE EARNINGS AND THE EQUITY PREMIUM
}

\author{
Francis A. Longstaff \\ Monika Piazzesi \\ Working Paper 10054 \\ http://www.nber.org/papers/w10054 \\ NATIONAL BUREAU OF ECONOMIC RESEARCH \\ 1050 Massachusetts Avenue \\ Cambridge, MA 02138 \\ October 2003
}

\begin{abstract}
We are grateful for helpful discussions with Tony Bernardo, John Cochrane, George Constantinides, Darrell Duffie, Jun Liu, Lee Ohanian, Pedro Santa-Clara, Tano Santos, Martin Schneider, and Pietro Veronesi. We are particularly grateful for the many helpful comments and suggestions of the editor William Schwert and of an anonymous referee. All errors are our responsibility. The views expressed herein are those of the authors and not necessarily those of the National Bureau of Economic Research.
\end{abstract}

(C)2003 by Francis A. Longstaff and Monika Piazzesi. All rights reserved. Short sections of text, not to exceed two paragraphs, may be quoted without explicit permission provided that full credit, including (C) notice, is given to the source. 
Corporate Earnings and the Equity Premium

Francis A. Longstaff and Monika Piazzesi

NBER Working Paper No. 10054

October 2003

JEL No. G1, E1

\section{$\underline{\text { ABSTRACT }}$}

Corporate cash flows are highly volatile and strongly procyclical. We examine the asset-pricing implications of the sensitivity of corporate cash flows to economic shocks within a continuous-time model in which dividends are a stochastic fraction of aggregate consumption. We provide closedform solutions for stock values and show that the equity premium can be represented as the sum of three components which we call the consumption-risk, event-risk, and corporate-risk premia. Calibrating to historical data, we show that the model implies a total equity premium many times larger than in the standard model. The model also generates levels of equity volatility consistent with those experienced in the stock market.

\section{Francis Longstaff}

UCLA

Anderson Graduate School of Management

110 Westwood Plaza, Box 951481

Los Angeles, CA 90095-1481

and NBER

francis.longstaff@anderson.ucla.edu

Monika Piazzesi

Graduate School of Business

University of Chicago

1101 E. 58th Street

Chicago IL 60637

and NBER

monika.piazzesi@gsb.uchicago.edu 


\section{INTRODUCTION}

Standard asset-pricing theory implies that equilibrium asset values can be expressed as the expected product of a pricing kernel and the cash flows from those assets. Because of this, the ultimate ability of an asset-pricing model to explain the equity premium hinges on being able to successfully identify an appropriate pricing kernel and accurately model corporate cash flows.

Since the equity premium puzzle was identified by Mehra and Prescott (1985), considerable progress has been made in specifying pricing kernels. Important recent examples include Eichenbaum, Hansen, and Singleton (1988), Sundaresan (1989), Constantinides (1990), Abel (1990), Epstein and Zin (1991), Ferson and Constantinides (1991), Detemple and Zapatero (1991), Heaton (1995), Chapman (1998), Campbell and Cochrane (1999), Hansen, Sargent, and Tallarini (1999), Lettau and Uhlig (2000), Wachter (2001), Chen and Epstein (2002), and many others.

In contrast, less attention has been paid to the problem of modeling corporate cash flows within this framework. In fact, many papers in this literature sidestep this issue altogether by simply constraining aggregate dividends to equal aggregate consumption. Important exceptions include Merton (1971) and Santos and Veronesi (2001) who model aggregate corporate cash flows as consumption minus a labor income component. Other important papers that allow aggregate cash flows to differ from aggregate consumption include Campbell (1986), Cecchetti, Lam, and Mark (1993), Campbell and Cochrane (1999), Abel (1999), Bekaert and Grenadier (1999), Brennan and Xia (2001), and others. In a series of insightful recent papers, Barberis and Huang (2001), and Menzly, Santos, and Veronesi (2002, 2003) model the cash flows of individual firms in a way that allows aggregate dividends to differ from aggregate consumption.

Modeling cash flows separately from aggregate consumption is crucial since corporate cash flows have historically been far more volatile and sensitive to economic shocks than has aggregate consumption. For example, corporate earnings have been more than ten times as volatile as consumption growth during the post-war period. Similarly, while aggregate consumption declined nearly 10 percent during the early stages of the Great Depression, aggregate corporate earnings were completely obliterated as they fell more than 103 percent. In addition to being more volatile, corporate cash flows are also highly correlated with aggregate consumption because of their strong procyclical behavior. To provide specifics, during the 1929 to 2001 period the volatility of earnings growth was 29.5 percent, while the correlation between per capita real consumption and earning growth was 68.7 percent. 
Intuitively, the reason for the extreme volatility and procyclicality of corporate earnings is that stockholders are residual claimants to corporate cash flows. Thus, the compensation of workers is a senior claim to cash flows. In other words, labor contracts provide workers with some degree of insurance against business cycle risk. These contracts make the fraction of labor income in output (or consumption) countercyclical, while the fraction of earnings in output is procyclical. Gomme and Greenwood (1995) document that these business-cycle-related changes in labor income and earnings can be found in many countries.

This paper extends the literature by modeling aggregate dividends as a small but highly volatile and procyclical component of aggregate consumption. The procyclicality and volatility of dividends directly impact the covariance between the pricing kernel and corporate cash flows and significantly affect equilibrium stock values. To capture the sensitivity of corporate cash flows to both the usual "small" economic shocks as well as to rare catastrophic "large" economic shocks, we extend the representative agent framework to allow aggregate dividends and consumption to follow distinct exponential-affine jump-diffusion processes. The ratio of aggregate dividends to consumption, which we designate the "corporate fraction," plays a central role in the model.

From the first-order conditions of the representative agent, we obtain an explicit closed-form expression for the stock price. In turn, this allows us to derive a simple expression for the equity premium in which there are three distinct components. The first is the standard Mehra and Prescott (1985) equity premium proportional to the variance of consumption growth, which we call the consumption-risk premium. The second is proportional to the probability of a jump times the product of the jump sizes in consumption and the stock price. We designate this jump-related component the event-risk premium. The third is proportional to the covariance between the growth rates in consumption and the corporate fraction, and is designated the corporate-risk premium. This three-component model of the equity premium nests many of the previous models in the literature and provides a number of new insights about the determinants of the equity premium.

To illustrate the model's asset-pricing implications, we calibrate the model using parameters that approximate the properties of consumption and the corporate fraction during the past century. A novel feature of our approach is that we calibrate the model using imputed dividends (calculated by applying a payout ratio, which we assume to be constant, to aggregate corporate earnings) rather than using reported dividends. The rationale for this stems from the well-known tendency of firms to artificially smooth their dividends over time, thereby delinking reported dividends from actual corporate cash flows.

We show that the high sensitivity of imputed dividends to economic shocks maps into equity premia many times larger than in the standard framework. For example, using a risk aversion coefficient of five, the three components of the equity premium 
are $0.36,0.51$, and 1.39 percent respectively, giving a total equity premium of 2.26 percent. Thus, the equity premium implied by the model is more than six times as large as the standard Mehra and Prescott (1985) equity premium (given by the first component). Similar results hold for a variety of other calibrations.

It is important to recognize, however, that the equity premium implied by the model is less than half as large as historical estimates. Thus, the model clearly does not provide a complete resolution of the equity premium puzzle. Moreover, the Euler equation for the riskfree bond in our model is the standard one, which means that we inherit Weil's (1989) riskfree rate puzzle. Our results do suggest, however, that combining our approach with other elements such as habit formation (as in Campbell and Cochrane (1999)) or investor heterogeneity in incomplete markets (see the discussion in Constantinides (2002)) could play an important role in the ultimate resolution of asset-pricing puzzles.

There is an extensive literature on the equity premium puzzle. Detailed references can be found in the excellent surveys by Kocherlakota (1996), Cochrane (1997), Campbell (1999), Constantinides (2002), and Mehra (2002). Breeden (1979) and Bakshi and Chen $(1996,1997)$ are continuous-time versions of the endowment economy in Lucas (1978) based on diffusions. Naik and Lee (1990) extend the setup to allow for jumps in consumption growth. Their model is the continuous-time analogue of Rietz (1988).

The remainder of this paper is organized as follows. Section 2 presents the assetpricing model. Section 3 solves for the equity premium generated by the model and examines its properties. Section 4 discusses the properties of the corporate fraction. Section 5 describes how the model is calibrated. Section 6 examines the asset-pricing implications of the model. Section 7 summarizes the results and makes concluding remarks.

\section{THE MODEL}

In this section, we extend the Lucas (1978) and Mehra and Prescott (1985) framework by introducing an explicit model of corporate cash flows. In this model, corporate cash flows represent a small but highly volatile fraction of aggregate consumption. This sensitivity to economic shocks has a number of important asset-pricing implications.

We consider an economy populated by a representative agent who maximizes an expected power utility function of the form,

$$
E_{t}\left[\int_{t}^{\infty} e^{-\delta(s-t)} \frac{C_{s}^{1-\gamma}}{1-\gamma} d s\right]
$$

where $C_{t}$ represents consumption, $\gamma$ is the coefficient of relative risk aversion, and $\delta$ is 
the subjective discount rate. The agent has two sources of a nondurable consumption good. First, the agent receives an exogenous endowment $I_{t}$ of the consumption good which constitutes his nonfinancial income. Second, the agent is also initially endowed with one share of a stock which pays dividends $D_{t}$ in the form of the consumption good. The stock is thus a claim to dividends instead of consumption, which in equilibrium is given by the sum of the dividends and nonfinancial income, $C_{t}=D_{t}+I_{t}$.

We specify the corporate fraction $F_{t}$ of dividends in consumption exogenously as,

$$
F_{t}=\frac{D_{t}}{C_{t}}=\exp \left(-X_{t}\right)
$$

where $X_{t}$ follows the square-root jump-diffusion process,

$$
d X=(\mu-\kappa X) d t-\eta \sqrt{X} d Z_{1}+\xi d q .
$$

Here, $Z_{1}$ is a standard Brownian motion and $q$ is a Poisson process with constant intensity $\lambda$. Provided that $\mu, \kappa$, and $\xi$ are positive, the value of $X_{t}$ is nonnegative. In turn, this ensures that the corporate fraction $F_{t}$ is always between zero and one. This property makes intuitive sense given the interpretation of $F_{t}$ as the proportion of total consumption that comes from dividends. It is easily shown that the expected value of the corporate fraction converges to a steady-state value as $s \rightarrow \infty$ because of the mean reverting nature of these dynamics.

We next assume that aggregate consumption follows the jump-diffusion process,

$$
\frac{d C}{C}=\alpha d t+\sigma \sqrt{X} d Z_{2}-\psi d q,
$$

where $0 \leq \psi<1$, and $Z_{2}$ is also a standard Brownian motion. The correlation between the two Brownian motions is $\rho d t$. By allowing changes in both $X_{t}$ and $C_{t}$ to be driven by Brownian motions, the model captures the sensitivity of dividends and consumption to small or continuous economic shocks. Furthermore, by allowing $\rho<1$, the model captures the feature that small changes in dividends can be influenced by factors other than those driving consumption. Because both $X_{t}$ and $C_{t}$ are affected by a common Poisson process, however, the model allows for large economic shocks or events (such as the Great Depression) to trigger simultaneous jumps in both dividends and consumption. Finally, note from Eq. (4) that expected consumption growth is constant, implying that consumption growth is not predictable. This follows Hall (1978), Campbell and Cochrane (1999), Chan and Kogan (2002), and many others who assume that consumption growth is not predictable.

From Eq. (2), dividends are given by, 


$$
D_{t}=C_{t} F_{t}=C_{t} \exp \left(-X_{t}\right)
$$

An application of Ito's Lemma implies the dynamics for the dividend process,

$$
\begin{aligned}
\frac{d D}{D}= & \left(\alpha-\mu+\left(\kappa+\rho \sigma \eta+\eta^{2} / 2\right) X\right) d t \\
& +\sigma \sqrt{X} d Z_{1}+\eta \sqrt{X} d Z_{2}+\left((1-\psi) e^{-\xi}-1\right) d q .
\end{aligned}
$$

Comparing these dynamics with those in Eq. (4) shows that dividends have the potential to be more volatile than consumption in this framework because dividend dynamics are driven by both Brownian motions. Similarly, these dynamics allow jumps in dividends to be larger than jumps in consumption. This feature is particularly important since it allows the model to avoid the Mehra and Prescott (1988) critique of the Rietz (1988) model. Rietz argues that the historical equity premium can be explained by the risk of large downward jumps (possibly as large as 90 percent) in consumption. Mehra and Prescott argue that the size of the downward jumps in consumption necessary to explain the equity premium is many times larger than any ever experienced in U.S. history. By allowing us to specify the jump in dividends separately from the jump in consumption, the model is in a better position to capture the historical equity premium without resorting to unrealistically large consumption crashes.

Taken together, these results imply that dividend growth is more sensitive to economic shocks whenever the corporate fraction is stochastic. Only in the case where the corporate fraction is deterministic are dividends and consumption growth equally sensitive to economic shocks. ${ }^{1}$ In this case, our model reduces to the standard Mehra and Prescott (1985) framework.

In equilibrium, the price of the stock satisfies the Euler equation,

$$
\begin{aligned}
P_{t} & =E_{t}\left[\int_{t}^{\infty} e^{-\delta(s-t)}\left(\frac{C_{s}}{C_{t}}\right)^{-\gamma} D_{s} d s\right] \\
& =E_{t}\left[\int_{t}^{\infty} e^{-\delta(s-t)}\left(\frac{C_{s}}{C_{t}}\right)^{-\gamma} C_{s} F_{s} d s\right] .
\end{aligned}
$$

\footnotetext{
${ }^{1}$ To see this, note from Eq. (3) that the corporate fraction is deterministic if and only if $\eta=\xi=0$. Substituting these values into Eq. (6) makes the stochastic components of the dynamics for $D$ identical to those for $C$ in Eq. (4).
} 
Using the results in Duffie, Pan, and Singleton (2000), the appendix shows that the stock price is given by the following closed-form expression,

$$
P_{t}=C_{t} \int_{t}^{\infty} e^{-\delta(s-t)} A(t, s) F_{t}^{-B(t, s)} d s
$$

where,

$$
A(t, s)=\exp \left(\int_{t}^{s}-\alpha(1-\gamma)-\mu B(t, u)-\lambda\left((1-\psi)^{1-\gamma} \exp (B(t, u) \xi)-1\right) d u\right)
$$

and $B(t, s)$ is given by,

$$
B(t, s)=\frac{\kappa+\rho \sigma \eta(1-\gamma)+\phi}{\eta^{2}}-\frac{2 \phi}{\eta^{2}\left(1-\theta e^{-\phi(s-t)}\right)},
$$

and where,

$$
\begin{aligned}
& \phi=\sqrt{(\kappa+\rho \eta \sigma(1-\gamma))^{2}-\eta^{2} \sigma^{2} \gamma(\gamma-1)}, \\
& \theta=\frac{\eta^{2}+\kappa+\rho \sigma \eta(1-\gamma)-\phi}{\eta^{2}+\kappa+\rho \sigma \eta(1-\gamma)+\phi} .
\end{aligned}
$$

From this closed-form solution, it is clear that the stock price is a complex function of consumption, the corporate fraction, and the parameters governing their dynamics. ${ }^{2}$

\section{THE EQUITY PREMIUM}

To explore the implications of the model for the equity premium, it is helpful to first simplify notation slightly. Let $\sigma_{C}$ and $\sigma_{F}$ denote the instantaneous volatility of percentage changes in consumption and the corporate fraction respectively. ${ }^{3}$ By a

${ }^{2}$ As discussed in the appendix, this solution requires that the term under the square root in the definition of $\phi$ be positive. Given typical parameter values, however, this condition is easily satisfied. Other recent papers that provide solutions for equity prices in terms of their fundamental cash flows include Ohlson (1990, 1995), Bakshi and Chen (1996, 1997, 2001), Bekaert and Grenadier (1999), Ang and Liu (2001), Vuolteenaho (2002), Mamaysky (2002), and Pastor and Veronesi (2003).

${ }^{3}$ More precisely, $\sigma_{C}$ and $\sigma_{F}$ denote the instantaneous volatility of the continuous portion of $d C / C$ and $d F / F$ respectively. 
simple extension of the results in Cochrane (2001) to jump-diffusion processes, the appendix shows that the equity premium EP implied by the model can be expressed as,

$$
E P=\gamma \sigma_{C}^{2}-\lambda J_{\Lambda} J_{P}+\gamma H \rho \sigma_{C} \sigma_{F},
$$

where $J_{\Lambda}$ is the percentage jump in marginal utility, $J_{P}$ is the percentage jump in the stock price, and $H$ is the elasticity of the stock price with respect to $F$.

This expression illustrates that the equity premium implied by the model has three distinct components. The first term, $\gamma \sigma_{C}^{2}$, corresponds to the equity premium implied by many traditional models (for example, see the recent review paper by Mehra (2002)). To make things more clear, we call this first component of the equity premium the consumption-risk premium. As is well known, this first term by itself generates a very small equity premium given the low volatility of historical aggregate consumption data and reasonable levels of the risk aversion coefficient. To provide a simple numerical illustration, assume a value for consumption volatility of three percent and a value of five for the risk aversion coefficient. From Eq. (9), this implies a value for the consumption-risk premium of only 0.45 percent.

The second term is directly related to the effect of a jump on the equilibrium price of the stock. A jump event has two potential effects on the Euler equation defining the price of the stock in that it affects both consumption and the dividend stream. In particular, a downward shock in consumption has the effect of increasing the representative agent's marginal utility. Thus, $J_{\Lambda}$ is positive. On the other hand, the shock to dividends results in a price decline, which means that $J_{P}$ is negative. Thus, the second term $-\lambda J_{\Lambda} J_{P}$ is positive in sign, and can be directly interpreted as the event-risk premium or jump component of the equity premium.

When jumps cannot occur, $\lambda=0$, and the event-risk premium becomes zero. Alternatively, if jumps affect only dividends and not consumption, $J_{\Lambda}=0$, and the event-risk premium is again zero. The presence of the event-risk component in the equilibrium equity premium parallels Rietz (1988) in which large downward jumps in consumption affect asset prices. Unlike Rietz, however, our model allows the jump in dividends to differ in size from the jump in consumption. As we show later, this allows the model to generate a large event-risk premium even when the downward jump in consumption is realistic by historical standards. To continue our numerical illustration, assume that a major event such as the Great Depression happens every 100 years on average, resulting in a 10 percent decline in consumption and a 75 percent decline in the stock market. The corresponding percentage increase in marginal utility $J_{\Lambda}$ is simply $\left(0.9^{-5}-1\right)$, or 69.4 percent. Thus, the event-risk premium is $0.01 \times 0.694 \times 0.750=$ 0.0052 , or 0.52 percent. This simple example shows that the event-risk premium can be larger than the usual Mehra and Prescott (1985) consumption-risk equity premium given jumps in consumption and the stock market similar to those during the early 
1930s.

The third term in the equity premium is directly related to the covariance between consumption growth and percentage changes in the corporate fraction. For example, if dividends are a constant fraction of consumption (as in Mehra and Prescott (1985)), then $\sigma_{F}=0$, which implies that this component of the equity premium is zero. Note that this is true even if the ratio of dividends to consumption is not one. Alternatively, if the correlation $\rho$ between the continuous changes in $C_{t}$ and $F_{t}$ is zero, then this component is again zero. We designate this third term the corporate-risk premium. To provide a realistic upper bound on how much the corporate-risk premium could potentially contribute to the total equity premium, consider the extreme case where both the correlation and elasticity coefficients are equal to one. Using values for $\sigma_{C}$ and $\sigma_{F}$ of 3 and 30 percent respectively, Eq. (9) implies a value for the corporate volatility premium of 4.50 percent, which is ten times as large as the consumption volatility premium. Totaling all three of the risk premia in this numerical illustration gives a rough upper bound for the equity premium of $0.45+0.52+4.50=5.47$ percent, which is clearly on the right order of magnitude. In the next several sections, we provide a simple approach for calibrating the model and examining more carefully its implications for the equity premium.

\section{MEASURING THE CORPORATE FRACTION}

One of distinguishing features of our framework is that dividends are explicitly modeled as a stochastic fraction of total consumption. Since this corporate fraction plays a key role throughout our framework, this section describes how the corporate fraction is estimated and provides summary statistics about its properties.

In theory, the corporate fraction could be estimated by taking reported aggregate dividends and dividing them by aggregate consumption. In actuality, however, there are important reasons why the resulting estimate of the corporate fraction may not be appropriate. Foremost among these is the extensive evidence that corporations tend to artificially smooth dividends over time. Specifically, firms tend to retain earnings within the firm during good periods, and pay dividends out of capital during bad periods. Evidence on this tendency dates back as far as Lintner (1956), Brittain (1966), and Fama and Babiak (1968). More recent examples documenting this tendency include Marsh and Merton (1987), DeAngelo, DeAngelo, and Skinner (1992), Allen and Michaely (2002), and many others. Clearly, if firms manage their dividends for reasons related to their information or signaling content (for example, as in Bhattacharya (1979), Miller and Rock (1985)), or to resolve agency conflicts (see Allen and Michaely), then the stochastic properties of reported dividends may not be directly linked to the actual cash flows generated by firms. Interestingly, Fama and French (2001) show that firms that do not pay any dividends now account for one-quarter of

the value of the stock market. In addition, as argued by Liang and Sharpe (1999), Hall 
(2001), and others, reported dividends may not include important cash distributions such as share repurchases or corporate acquisitions. Allen and Michaely document that the amount of share repurchases is much more volatile than dividends. ${ }^{4}$ These considerations provide a compelling motivation for using a measure of dividends that more closely reflects actual corporate cash flows.

To this end, we adopt the intuitive approach of assuming that aggregate "economic" dividends are equal to a constant payout ratio times aggregate corporate earnings. This approach is used in a number of recent papers such as Lee, Myers, and Swaminathan (1999), Bakshi and Chen (2001), and others. Furthermore, this approach is consistent with the evidence by Lintner (1956), Fama and Babiak (1968), and others that dividend policy is well described by a model in which firms apply a target payout ratio to earnings in making dividend decisions. An important feature of this approach is that percentage changes in imputed dividends are equal to percentage changes in earnings. Thus, the volatility and correlation properties of growth rates in imputed dividends mirror those of corporate earnings.

To provide historical perspective, we collect data on the corporate fraction for the period from 1929 to 2001 . The inclusion of the 1930s in the sample is particularly important given the peso-problem-like difficulty in estimating the size and frequency of catastrophic events which could lead to a significant event-risk component in the equity premium. The annual earnings and consumption data used to compute $F_{t}$ are from the National Income and Product Accounts (NIPA) reported by the Bureau of Economic Analysis. As the earnings measure, we use total after-tax corporate profits. We use after-tax rather than pre-tax earnings since dividends are not tax deductible at the corporate level and must be paid out to shareholders on an after-tax basis (see McGrattan and Prescott (2001) for a discussion of the effects of taxes on the equity premium).

Although it could be argued that firms also manage their earnings, there are a number of reasons why this measure of earnings should be largely free of this problem. First, NIPA corporate profit measures are based on Federal tax law rather than on the set of more-flexible rules used by corporations and accounting firms to report financial results to shareholders (typically referred to as GAAP or Generally Accepted Accounting Principles). Second, the NIPA earnings measure avoids many of the "extraordinary" items that firms report since the NIPA earnings measure excludes capital gains and losses, losses resulting from bad debts, interfirm cash flows, depletion, etc. Finally, since these numbers are aggregated over all firms, any idiosyncratic "extraordinary" items that may cause earnings volatility at the firm level may have little influence on volatility of aggregate earnings. ${ }^{5}$

\footnotetext{
${ }^{4}$ For an analysis of the tradeoffs between paying dividends and repurchasing shares, see Chowdhry and Nanda (1994) and Allen, Bernardo, and Welch (2000).

${ }^{5}$ For example, if a transaction involves one firm reporting an extraordinary gain and
} 
It is important to note that the NIPA measure of earnings does not simply equal total consumption minus labor income. The reason for this is that the National income accounts also include components such as proprietors' income, rental income, and net interest. We exclude these components in our measure of earnings since our focus is on valuing equity claims, and these components do not accrue to corporate shareholders. ${ }^{6}$ Consumption is defined as the sum of aggregate nondurable and services consumption. In computing real growth rates in consumption, our estimates of realized inflation are based on the price series corresponding to our definition of consumption (not the CPI). Year-end population estimates used to calculate per capita consumption are from the Census Bureau. Consistent with the historical average for this period, we assume that the payout ratio is 50 percent. $^{7}$ We note, however, that varying the payout ratio has little effect on the any of the results.

Fig. 1 plots the time series of the corporate fraction for the 1929 to 2001 period. As shown, one of the most striking features of the corporate fraction is its volatility. The corporate fraction ranges from a low of -2.11 percent in 1932 to a maximum of 7.81 percent in 1959 . The average value of the corporate fraction is 4.92 percent. The standard deviation (in levels) of the corporate fraction is 1.62 percent, which is a ratio of 32.99 percent of its mean value. This ratio closely parallels the 27.03 percent standard deviation of percentage changes in the corporate fraction. ${ }^{8}$ Another indication of the extreme sensitivity of the corporate fraction to economic shocks is that while consumption declined 8.91 percent during the early stages of the Great Depression, the corporate fraction declined 103.35 percent. The first-order serial correlation of percentage changes in the corporate fraction is 0.058 .

Another key feature of the corporate fraction is its surprisingly high correlation with consumption. Specifically, during the 1929-2001 sample period (excluding 1931 and 1932), the correlation between percentage changes in the corporate fraction and

another an offsetting extraordinary loss, the aggregate should be largely unaffected. Furthermore, a recent survey by the American Institute of Certified Public Accountants estimates that fewer than ten percent of firms report extraordinary items.

${ }^{6}$ This is a key distinction between our approach and other papers in the literature that model aggregate dividends as aggregate consumption minus some measure of aggregate labor income.

${ }^{7}$ For example, from 1929 to 2001, the median payout ratio is 46.5 percent, and the average payout ratio (excluding the two years with negative earnings) is 54.6 percent. Allen and Michaely (2002) Table 1 implies an average dividend payout ratio of 45.2 percent from 1972 to 1998.

${ }^{8}$ Since earnings for 1931-32 are negative, we compute the percentage changes in the corporate fraction for these years relative to 1930 and then annualize the percentages. Note that this likely results in the volatility of percentage changes being understated. 
consumption growth is 0.632 . This is shown in Fig. 2. which plots the percentage changes in the corporate fraction against those of consumption growth. Clearly, there is a strong positive correlation between the two variables; the $t$-statistic for consumption growth from the regression of percentage changes in the corporate fraction on consumption growth is 6.54 . Thus, the corporate fraction varies significantly with the business cycle; the corporate fraction is highly procyclical. In particular, a one-percent decline in consumption is associated with roughly a six-percent decline in the corporate fraction. In turn, this implies about a seven-percent decline in dividends. This procyclicality of dividends has important implications for the size of the corporate-risk premium.

There are a number of important theoretical and empirical reasons why the corporate fraction should be strongly procyclical. The distribution of income between capital and labor income plays a critical role throughout much of the macroeconomic literature during the past several decades. One of the main components of capital income is corporate profits (the other components are net interest, rental income, and depreciation). As documented by Gomme and Greenwood (1995), the share of income going to capital is highly procyclical in the U.S. as well as in the eight other OECD countries they study. This share approximates the corporate fraction if one thinks of capital income as being mostly corporate profits and of consumption as being roughly equal to income. Gomme and Greenwood show that this procyclicality arises naturally in a model where entrepreneurs insure workers against business cycle fluctuations. Entrepreneurs (or shareholders) therefore become residual claimants to corporate cash flows.

To provide additional empirical evidence about the procyclicality of the corporate fraction, we investigated a number of alternative approaches for estimating the correlation. For example, using the extensive historical data set on stock prices, earnings, and consumption collected by Shiller (1989), we calculate the correlation between annual growth rates for real per capita consumption and earnings on the S\&P Composite Stock Price Index for the 1889-1985 period. Although earnings on the S\&P index represent only a small proportion of aggregate corporate profits, the estimated correlation of 0.454 is similar to that based on the NIPA data. Shiller explains that prior to 1926, S\&P does not report earnings on the index and that earnings data for the pre-1926 period are based on average price-earnings ratios. Using only the data for the 1926-1985 period, the correlation estimate is $0.568 .^{9}$

As an alternative measure of the corporate fraction, we collected data from the 2002 Economic Report of the President about aggregate corporate income tax and total income tax revenues from the period from 1959 to 2001. Using the ratio of corporate income tax revenues to total income tax revenues as a proxy for the corporate

${ }^{9}$ The correlation for the 1889 to 1985 period excludes the crash of 1921-1922 since this represents a large jump event. 
fraction, the correlation between percentage changes in the corporate fraction and in real per capita consumption is 0.546 . We apply a similar income tax revenue based approach to estimate the corporate fraction in several other countries for which we could find tax data. Using data from the Inland Revenue Service of the U.K., the correlation between annual percentage changes in the corporate fraction and real per capita consumption in the U.K. is 0.490 for the period from 1978 to 2002. Similarly, using data from the Department of Finance for Canada, the correlation between percentage changes in the corporate fraction and real per capita consumption in Canada is 0.436 for the period from 1962 to 2002. Although the ratio of corporate to total income tax revenues is clearly a noisy estimate of the corporate fraction (i.e., it is affected by changes in tax rates, by the progressivity of tax rates, etc.), these high correlations provide independent support for the strong correlation of the corporate fraction and consumption found in the NIPA data. ${ }^{10}$

\section{MODEL CALIBRATION}

In examining the asset-pricing implications of the model, our approach is to first provide a simple benchmark calibration that captures the historical properties of the data. To provide more insight into these asset-pricing implications, however, we also report results using a range of realistic alternative values for a number of key model parameters.

First, to hold fixed the properties of the pricing kernel throughout the analysis, the results are all based on a modest level of five for the risk aversion coefficient $\gamma$ of the representative agent. We also assume that the subjective discount rate $\delta$ is 0.01 .

Second, to calibrate the jump-related parameters, we use estimates that reflect the U.S. experience during the Great Depression. In particular, we use a benchmark value for $\lambda$ of 0.01 , implying that a major economic crash occurs every 100 years on average. This mean frequency may actually be overly conservative given the experience of other major economies such as Germany and Japan during the past century. For the consumption jump size $\psi$, we assume a downward jump of 10 percent. This value is consistent with 8.9 percent downward jump in consumption during 1932, and the 16 percent decline from 1929 to $1932 .{ }^{11}$ Next, we assume that the realization of the

\footnotetext{
${ }^{10}$ We also found data sources from the Ministry of Finance for Japan in which a measure of aggregate pre-tax corporate profits is reported. Using this to calculate the corporate fraction, the correlation between the corporate fraction and consumption is 0.284 for the 1960 to 2001 period.

${ }^{11}$ While downward jumps in consumption of this magnitude are large, there are many examples of economies that have experienced downward jumps in consumption of as much as 20 to 30 percent during the past 50 years. In particular, countries that have experienced a one-year decline in real GDP of more than 20 percent since 1950 include
} 
Poisson event in the model results in a 90 percent decrease in corporate earnings and imputed dividends. Again, this is on the conservative side given the more than 103 percent decline in corporate earnings during the early stages of the Great Depression.

Third, consistent with the properties of consumption during the 1929 to 2001 period, we assume that the instantaneous mean and standard deviation of consumption growth are 2.34 and 2.86 percent respectively. ${ }^{12}$ Setting these values equal to the instantaneous first and second moments implied by Eq. (4) gives the following simple expressions,

$$
\begin{aligned}
0.0234 & =\alpha-\lambda \psi, \\
0.0286^{2} & =\lambda \psi^{2}-\sigma^{2} \ln \bar{F},
\end{aligned}
$$

which are easily solved for $\alpha$ and $\sigma$. Here, the moments are evaluated at the average value $\bar{F}=0.0492$ of the corporate fraction in the sample.

Fourth, the appendix shows that the expected instantaneous change in the corporate fraction is positive for small values of $F$ and negative for large values of $F$. Setting this expected change equal to zero when the corporate fraction equals $\bar{F}$ and using a value of 27.03 percent for the instantaneous volatility of the fraction implies the following two expressions,

$$
\begin{aligned}
0 & =-\mu-\left(\kappa+\eta^{2} / 2\right) \ln \bar{F}+\lambda\left(e^{-\xi}-1\right), \\
0.2703^{2} & =-\eta^{2} \ln \bar{F}+\lambda\left(e^{-\xi}-1\right)^{2},
\end{aligned}
$$

which likewise are easily solved for the parameters $\mu$ and $\eta$. For $\kappa$, we use a value of 0.058 , matching the first-order serial correlation coefficient for percentage changes in the corporate fraction during the sample period. Finally, given the properties of the corporate fraction described in the previous section, we use a value of 0.632 for the correlation parameter $\rho$. Table 1 summarizes the calibration assumptions and parameters. ${ }^{13}$

Algeria, Angola, Chad, Iran, Iraq, Namibia, Nicaragua, Niger, Nigeria, Sierra Leone, and Uganda (see Heston and Summers (1991)).

${ }^{12}$ Table 3 of Campbell (1999) reports that the mean and standard deviation of consumption growth during the 1891 to 1995 period are 1.77 and 3.26 percent respectively. ${ }^{13}$ The standard deviation of earnings growth rates during the 1929 to 2001 sample period is 29.5 percent. The correlation of per capita real consumption and earnings growth rates during the same period (excluding 1931 and 1932) is 68.7 percent. 


\section{ASSET-PRICING IMPLICATIONS}

Given this benchmark calibration, it is now straightforward to solve for the equity premium and its components. Table 2 reports the values of the equity premium implied by the benchmark calibration. Also reported in Table 2 are values implied by alternative sets of some of the key parameters of this model.

As shown, the total equity premium is 2.26 percent in the benchmark case. This equity premium consists of a 0.36 percent consumption-risk premium, a 0.51 percent event-risk premium, and a 1.39 percent corporate-risk premium. Note that the total equity premium implied by this calibration is more than six times as large as the traditional Mehra and Prescott (1985) equity premium (given by the first or consumptionrisk component). Thus, this approach of explicitly modeling corporate cash flows and calibrating the model to earnings data clearly can increase the equilibrium equity premium by nearly an order of magnitude.

Table 2 also shows the sensitivity of the equity premium to some of the key parameters that are unique to this modeling framework. As shown, the mean value of the corporate fraction has only a second-order effect on the equity premium. In contrast, the volatility of changes in the corporate fraction, the correlation coefficient, and the serial correlation coefficient all have large effects on the equity premium. Furthermore, this effect comes predominantly (but not exclusively) through their effects on the corporate-risk component of the equity premium. Finally, an increase in the risk of a large economic shock has the effect of significantly increasing the total equity premium. Note, however, that as the probability of a large jump increases, the volatility of the continuous shocks in $C$ and $F$ must decrease to hold fixed the total volatility of percentage changes in these variables. Thus, both the consumption-risk and corporate-risk premia decrease as the probability of a jump increases.

Although not shown, we also examine the sensitivity of the equilibrium equity premium to a number of the other parameters in the model. These results indicate that the effects of changes in parameters such as risk aversion coefficient, the volatility of consumption, and the size of the jumps in consumption or the corporate fraction are exactly as implied by the expression for the equity premium in Eq. (9). Not surprisingly, changes in the subjective discount rate and the expected growth rate of consumption have very little effect on the equity premium. Finally, changes in the assumed payout ratio have virtually no effect on the equity premium.

By applying Ito's Lemma to the closed-form solution for the stock price, it is straightforward to solve for the instantaneous volatility of stock returns. Using the parameters for the benchmark scenario gives a stock return volatility measure of 17.37 percent. This closely approximates the actual volatility of market returns during most

of the past century. For example, the annualized volatility of monthly returns on the CRSP value-weighted index for the period from 1929 to 2000 is 19.20 percent. 
Given the closed-form solution for equity values in the model, it is also straightforward to solve for the effect of a catastrophic event or jump on the stock value. Under the benchmark scenario, the stock value declines by 74.15 percent when a jump event occurs. While this is clearly much larger than the associated 10 percent decline in consumption, it is significantly less than the 90 percent decline in dividends. Intuitively, equity values decline less than dividends since the mean reversion in the corporate fraction implies that the effects of a jump downwards are not permanent. The 74.15 percent value for the benchmark scenario is in close agreement with the historical evidence from the Great Depression. For example, the Dow Jones 30 stock index declined by 69 percent during the two-year 1930-1931 period. During 1931 alone, the Dow Jones 30 index fell by 53 percent.

Although our model is calibrated to U.S. data, these results are also consistent with the experience of many other major countries which have undergone large economic shocks. For example, Jorion and Goetzmann (1999) report stock market returns for countries which experienced shocks severe enough to result in temporary stock market closures. Specifically, they report the return for the period from just prior to the closure to the date of reopening. Their Table IV reports that Greece experienced a 58 percent decline, Japan, a 95 percent decline, Germany, a 84 percent decline, and Portugal, a 86 percent decline during the periods of closures. Of course, there are countries such as China where the economic shocks were so severe that investors presumably lost 100 percent of the value of their stockholdings.

\section{CONCLUSION}

We explore the asset-pricing implications of allowing cash flows to differ from aggregate consumption in a representative agent model with power utility. To model cash flows, we specify processes for consumption and the fraction of dividends in aggregate consumption, which we call the corporate fraction. Consistent with their historical properties, we model these processes as affine jump-diffusions. We show that equilibrium stock prices can be computed in closed form in this economy.

To measure cash flows, we assume a constant payout ratio and use aggregate data on earnings. The resulting cash flow series is more sensitive to economic shocks, including catastrophic shocks, than data on aggregate consumption. The series is also highly correlated with consumption growth. These two empirical properties are key features of our calibration.

For calibrated parameter values, we find that our model is able to generate an equity premium that is many times larger than in the standard model. We can write the equity premium in our model as the sum of three components. The first component is the standard consumption-risk premium. This component is small, because

consumption growth is smooth. The second component is an event-risk premium due 
to large catastrophic shocks, such as the Great Depression. Even under conservative assumptions on the probability of a large catastrophic shock and the size of its impact on earnings and consumption, we find that this component is already larger than the first. The third component is the corporate-risk premium. As cash flows are volatile and highly correlated with consumption growth, the third component represents the largest portion of the equity premium. We also compute the volatility of equilibrium returns. We find that our model is able to match the return volatility in the data. 


\section{APPENDIX}

\section{Solving for the Stock Price.}

Let $Y_{t}$ denote $\ln C_{t}$. Taking the expectation inside the integral in Eq. (7) requires evaluating terms of the form,

$$
E_{t}\left[\exp \left(-X_{s}+(1-\gamma) Y_{s}\right)\right] .
$$

From Duffie, Pan, and Singleton (2000) Proposition 1, these expectations can be expressed in the following form,

$$
A(t, s) \exp \left(B(t, s) X_{t}+C(t, s) Y_{t}\right)
$$

where $A(t, s), B(t, s)$, and $C(t, s)$ satisfy the system of ordinary differential equations,

$$
\begin{aligned}
& \frac{A^{\prime}}{A}=-\alpha C-\mu B-\lambda\left[(1-\psi)^{C} \exp (B \xi)-1\right], \\
& B^{\prime}=\sigma^{2}\left(C-C^{2}\right) / 2+(\kappa+\rho \sigma \eta C) B-\eta^{2} B^{2} / 2, \\
& C^{\prime}=0,
\end{aligned}
$$

subject to the boundary conditions $A(s, s)=1, B(s, s)=-1$, and $C(s, s)=1-\gamma$. From (A5), it is immediate that $C(t, s)=1-\gamma$. Substituting this expression for $C(t, s)$ into (A4) gives a simple Riccati equation for $B(t, s)$ which can be solved by a direct integration. Given typical parameter values, the term under the square root in the definition of $\phi$ is positive and the solution for $B(t, s)$ is as shown in Eq. (8). When the term under the square root in the definition of $\phi$ is negative, there is a periodic solution for $B(t, s)$ which can become infinite as $s \rightarrow \infty$. With little loss of generality, we abstract from this periodic solution and require the parameter values to be such that $\phi$ is well defined. The term $A(t, s)$ is then given by direct integration once $C(t, s)$ is substituted into (A5).

With the solutions for $A(t, s), B(t, s)$, and $C(t, s)$, we substitute the expression in (A2) into Eq. (7). Dividing this expression for the expectation by the $C_{t}^{-\gamma}=$ $\exp \left(-\gamma Y_{t}\right)$ term that appears in the denominator of the agent's marginal utility implies that the solution is linear in $C_{t}$. Recall that $F_{t}=e^{-X_{t}}$, which implies $\exp \left(B(t, s) X_{t}\right)=F_{t}^{-B(t, s)}$. Substituting this into Eq. (7) gives Eq. (8). 


\section{The Dynamics of the Corporate Fraction.}

Recall that $X_{t}=-\ln F_{t}$. Applying Ito's Lemma to $F_{t}=e^{-X_{t}}$ implies the dynamics,

$$
\frac{d F}{F}=\left(-\mu-\left(\kappa+\eta^{2} / 2\right) \ln F\right) d t+\eta \sqrt{-\ln F} d Z_{1}+\left(e^{-\xi}-1\right) d q .
$$

Since $X_{t}$ is nonnegative, $F_{t}$ takes values between zero and one. It is also easily shown that $F_{t}$ has a stationary long-run mean value (by solving for the value of $E_{t}\left[e^{-X_{s}}\right]$ and taking the limit as $s \rightarrow \infty)$. That $F_{t}$ displays mean reverting behavior is also clear from its dynamics. In particular, since $\ln F_{t}<0$, the drift term in (A6) is positive for values of $F_{t}$ close to zero, and is negative for values of $F_{t}$ close to one. Taking expectations in (A6) implies,

$$
E_{t}\left[\frac{d F}{F}\right]=\left(-\mu-\left(\kappa+\eta^{2} / 2\right) \ln F\right) d t+\lambda\left(e^{-\xi}-1\right) d t .
$$

Setting the left-hand side of (A7) equal to zero and evaluating at $F=\bar{F}$ gives Eq. (12). Similarly,

$$
\operatorname{Var}_{t}\left[\frac{d F}{F}\right]=-\eta^{2} \ln F d t+\lambda\left(e^{-\xi}-1\right)^{2} d t
$$

which implies Eq. (13) when evaluated at $F=\bar{F}$.

\section{The Equity Premium.}

Following Cochrane (2001), let $\Lambda_{t}$ denote the stochastic discount factor $e^{-\delta t} C_{t}^{-\gamma}$ and $P_{t}$ the price of the stock. Using the generalized form of Ito's Lemma to allow for jumps, Cochrane Eq. (1.32) can be expressed,

$$
d(\Lambda P)=P d \Lambda^{*}+\Lambda d P^{*}+d P^{*} d \Lambda^{*}+\left[\Lambda^{+} P^{+}-\Lambda P\right] d q,
$$

where changes in the processes superscripted with an asterisk denote continuous changes, and $\Lambda^{+}$and $P^{+}$denote the values of these processes immediately after a jump. Using this expression, Cochrane Eq. (1.33) becomes,

$$
0=\frac{D}{P} d t+E_{t}\left[\frac{d \Lambda^{*}}{\Lambda}+\frac{d P^{*}}{P}+\frac{d P^{*}}{P} \frac{d \Lambda^{*}}{\Lambda}\right]+\lambda\left[\frac{\Lambda^{+} P^{+}}{\Lambda P}-1\right] d t .
$$

Using the following expressions, 


$$
\begin{aligned}
& \frac{d P}{P}=\frac{d P^{*}}{P}+\left[\frac{P^{+}}{P}-1\right] d q, \\
& \frac{d \Lambda}{\Lambda}=\frac{d \Lambda^{*}}{\Lambda}+\left[\frac{\Lambda^{+}}{\Lambda}-1\right] d q,
\end{aligned}
$$

to substitute out terms in (A10) gives,

$$
\begin{gathered}
0=\frac{D}{P} d t+E_{t}\left[\frac{d \Lambda}{\Lambda}\right]+E_{t}\left[\frac{d P}{P}\right]+ \\
E_{t}\left[\frac{d P^{*}}{P} \frac{d \Lambda^{*}}{\Lambda}\right]+\lambda\left[\frac{\Lambda^{+} P^{+}}{\Lambda P}-\frac{P^{+}}{P}-\frac{\Lambda^{+}}{\Lambda}+1\right] d t .
\end{gathered}
$$

Rearranging terms and using Eq. (1.34) of Cochrane gives,

$$
E P d t=-E_{t}\left[\frac{d P^{*}}{P} \frac{d \Lambda^{*}}{\Lambda}\right]-\lambda\left(\frac{\Lambda^{+}}{\Lambda}-1\right)\left(\frac{P^{+}}{P}-1\right) d t
$$

An application of Ito's Lemma implies,

$$
\begin{aligned}
& \frac{d P^{*}}{P}=(\cdot) d t+\left(\frac{d C^{*}}{C}\right)+\left(\frac{F P_{F}}{P}\right)\left(\frac{d F^{*}}{F}\right), \\
& \frac{d \Lambda^{*}}{\Lambda}=(\cdot) d t-\gamma\left(\frac{d C^{*}}{C}\right) .
\end{aligned}
$$

Substituting into (A14), taking expectations, and using the notation introduced in the text now gives Eq. (9). 


\section{REFERENCES}

Abel, Andrew B., 1990. Asset prices under habit formation and catching up with the Jones. American Economic Review 80, 38-42.

Abel, Andrew B., 1999. Risk premia and term premia in general equilibrium. Journal of Monetary Economics 43, 3-33.

Allen, Franklin, Antonio E. Bernardo, and Ivo Welch, 2000. A theory of dividends based on tax clienteles. Journal of Finance 55, 2499-2536.

Allen, Franklin, and Roni Michaely, 2002. Payout policy. Working paper, Wharton.

Ang, Andrew, and Jun Liu, 2001. A generalized affine earnings model. Review of Accounting Studies 6, 397-415.

Bakshi, Gurdip, and Zhiwu Chen, 1996. Inflation, asset prices, and the term structure of interest rates in monetary economies. Review of Financial Studies 9, 237-271.

Bakshi, Gurdip, and Zhiwu Chen, 1997. An alternative valuation model for contingent claims. Journal of Financial Economics 44, 123-165.

Bakshi, Gurdip, and Zhiwu Chen, 2001. Stock valuation in dynamic economies. Working paper, University of Maryland.

Barberis, Nicholas, and Ming Huang, 2001, Mental accounting, loss aversion, and individual stock returns. Journal of Finance 56, 1247-1292.

Bekaert, Geert, and Steven R. Grenadier, 1999. Stock and bond pricing in an affine economy. NBER working paper 7346.

Bhattacharya, Sudipto, 1979. Imperfect information, dividend policy, and "the Bird in the Hand" fallacy. Bell Journal of Economics 10, 259-270.

Breeden, Douglas, 1979. An intertemporal asset pricing model with stochastic consumption and investment opportunities. Journal of Financial Economics 7, 265-296.

Brennan, Michael, and J. Xia, 2001. Stock price volatility, learning, and the equity premium. Journal of Monetary Economics 47, 249-283.

Brittain, J. A., 1966. Corporate Dividend Policy. Washington, D.C.: Brookings.

Campbell, John, 1986. Bond and stock returns in a simple exchange model. Quarterly Journal of Economics 101, 785-804.

Campbell, John, 1999. Asset prices, consumption and the business cycle. in Handbook of Macroeconomics vol 1c, 1231-1303, eds. John B. Taylor and Michael Woodford, 
Elsevier, Amsterdam.

Campbell, John, and John Cochrane, 1999. By force of habit: A consumption-based explanation of aggregate stock market behavior. Journal of Political Economy 107, 205-251.

Cecchetti, Steven G., Pok-Sang Lam, and Nelson C. Mark, 1993. The equity premium and the risk-free rate: Matching the moments. Journal of Monetary Economics 31, $21-46$.

Chan, Yeung Lewis, and Leonid Kogan, 2002. Catching up with the Joneses: Heterogeneous preferences and the dynamics of asset prices. Journal of Political Economy $110,1255-1285$.

Chapman, David A., 1998. Habit formation and aggregate consumption. Econometrica $66,1223-1230$.

Chen, Zengjing, and Larry Epstein, 2002. Ambiguity, risk and asset returns in continuous time. Econometrica 70, 1403-1443.

Chowdhry, Bhagwan, and Vikram Nanda, 1994. Repurchase premia as a reason for dividends: A dynamic model of corporate payout policies. Review of Financial Studies 7, 321-350.

Cochrane, John H., 1997. Where is the market going? Uncertain facts and novel theories. Economic Perspectives 21, 3-37.

Cochrane, John H., 2001, Asset Pricing.: Princeton University Press, Princeton, New Jersey.

Constantinides, George, 1990. Habit formation: A resolution of the equity premium puzzle. Journal of Political Economy 98, 519-543.

Constantinides, George, 2002, Rational asset pricing. Journal of Finance 57, 1567-1592.

Deangelo, Harry, Linda Deangelo, and Douglas J. Skinner, 1992. Dividends and losses, Journal of Finance 47, 1837-1863.

Detemple, Jerome, and Fernando Zapatero, 1991. Asset prices in an exchange economy with habit formation. Econometrica 59, 1633-1658.

Duffie, Darrell, Jun Pan, and Kenneth Singleton, 2000. Transform analysis and asset pricing for affine jump-diffusions. Econometrica 68, 1343-1376.

Eichenbaum, Martin, Hansen, Lars. P., and Kenneth Singleton, 1988. A time series analysis of representative consumer models of consumption and leisure choice under uncertainty. Quarterly Journal of Economics 103, 51-78. 
Epstein, Larry G., and Stanley E. Zin, 1991. Substitution, risk aversion, and the temporal behavior of consumption and asset returns: An empirical analysis. The Journal of Political Economy 99, 263-286.

Fama, Eugene F., and H. Babiak, 1968. Dividend policy: An empirical analysis. Journal of the American Statistical Association 63, 1132-1161.

Fama, Eugene F., and Kenneth R. French, 2001. Disappearing dividends: Changing firm characteristics or increased reluctance to pay? Journal of Financial Economics $60,3-43$.

Ferson, Wayne and George Constantinides, 1991. Habit persistence and durability in aggregate consumption: Empirical tests. Journal of Financial Economics 29, 199240.

Gomme, Paul, and Jeremy Greenwood, 1995, On the cyclical allocation of risk, Journal of Economic Dynamics and Control 19, 91-124.

Hall, Robert E., 1978. Stochastic implications of the life cycle-permanent income hypothesis: Theory and evidence. Journal of Political Economy 86, 971-987.

Hall, Robert E., 2001. The stock market and capital accumulation. American Economic Review 91, 1185-1202.

Hansen, Lars. P., Thomas J. Sargent, and Thomas Tallarini, 1999. Robust permanent income and pricing. Review of Economic Studies 66, 873-907.

Heaton, John, 1995. An empirical investigation of asset pricing with temporally dependent preference specifications. Econometrica 63, 681-718.

Heston, Alan, and Robert Summers, 1991. The Penn World Table (Mark 5): An expanded set of international comparisons, 1950-1988. Quarterly Journal of Economics, 327-368.

Jorion, Philippe, and William N. Goetzman, 1999. Global stock markets in the twentieth century. Journal of Finance 54, 953-980.

Kocherlakota, Narayana R., 1996. The equity premium: It's still a puzzle. Journal of Economic Literature 34, 42-71.

Lee, Charles, James Myers, and Bhaskaran Swaminathan, 1999. What is the intrinsic value of the Dow?, Journal of Finance 54, 1693-1741.

Lettau, Martin, and Harald Uhlig (2000). Can habit formation be reconciled with business cycle facts? Review of Economic Dynamics 3, 79-99.

Liang, J. Nellie, and Steven A. Sharpe, 1999. Share repurchases and employee stock 
options and their implications for $\mathrm{S} \& \mathrm{P} 500$ share retirements and expected returns. Working paper, Federal Reserve Board.

Lintner, John V., 1956. Distribution of incomes of corporations among dividends, retained earnings, and taxes. American Economic Review 46, 97-113.

Lucas, Robert, 1978. Asset prices in an exchange economy. Econometrica 46, 1429-1445.

McGrattan, Ellen R. and Edward C. Prescott, 2001. Taxes, regulations, and asset prices. NBER working paper 8623, December.

Mamaysky, Harry, 2002. A model for pricing stocks and bonds. Working paper, Yale University.

Marsh, Terry A., and Robert C. Merton, 1987. Dividend behavior for the aggregate stock market. Journal of Business 60, 1-40.

Mehra, Rajnish, 2002. The Equity Premium: Why is it a puzzle? Financial Analyst Journal, forthcoming.

Mehra, Rajnish, and Edward C. Prescott, 1985. The equity premium puzzle. Journal of Monetary Economics 15, 145-161.

Mehra, Rajnish, and Edward C. Prescott, 1988. The equity premium puzzle: A solution? Journal of Monetary Economics 22, 133-136.

Menzly, Lior, Tano Santos, and Pietro Veronesi, 2002. Habit formation and the cross section of stock returns. Working paper, The University of Chicago.

Menzly, Lior, Tano Santos, and Pietro Veronesi, 2003, The time series of the cross section of asset prices. Working paper, The University of Chicago.

Merton, Robert, 1971. Optimum consumption and portfolio rules in a continuous time model. Journal of Economic Theory 3, 373-413.

Miller, Merton H., and Kevin Rock, 1985. Dividend policy under asymmetric information. Journal of Finance 40, 103-151.

Naik, Vasanttilak, and Moon Lee, 1990. General equilibrium pricing of options on the market portfolio with discontinuous returns. Review of Financial Studies 3, 493-521.

Ohlson, James A., 1990. A synthesis of security valuation theory and the role of dividends, cash flows, and earnings. Journal of Contemporary Accounting Research 6, 648-676.

Ohlson, James A., 1995. Earnings, book values, and dividends in equity valuation. Journal of Contemporary Accounting Research 11, 661-687. 
Pastor, Lubos, and Pietro Veronesi, 2003, Stock valuation and learning about predictability. Journal of Finance, forthcoming.

Rietz, Thomas, 1988. The equity premium puzzle: A solution? Journal of Monetary Economics 21, 117-132.

Santos, Tano, and Pietro Veronesi, 2001. Labor income and predictable stock returns. NBER working paper 8309, May.

Shiller, Robert J., 1989, Market Volatility, MIT Press, Cambridge, MA.

Sundaresan, Suresh, 1989, Intertemporal dependent preferences and the volatility of consumption and wealth. The Review of Financial Studies 2, 73-88.

Vuolteenaho, Tuomo, 2002. What drives firm-level stock returns? Journal of Finance $57,233-264$.

Wachter, Jessica, 2001, Habit formation and returns on bonds and stocks. Working paper, NYU.

Weil, Pierre, 1989. The equity premium puzzle and the risk-free rate puzzle. Journal of Monetary Economics 24, 401-421. 
Table 1

Benchmark Calibration Values. This table reports the values for the indicated calibration inputs. The parameter estimates are based on NIPA data on annual real per capita consumption and after-tax corporate earnings for the 1929 to 2001. Consumption is defined as the sum of aggregate nondurable and services consumption. Jump size parameters correspond to the approximate magnitude of the decline in consumption and the corporate fraction during the early stages of the Great Depression. Consumption growth and volatility represent the mean and standard deviation of annual percentage changes in real per capita consumption. Mean corporate fraction is the time series average of the corporate fraction. Fraction volatility and autocorrelation are the indicated moments for annual percentage change in the corporate fraction. The correlation coefficient represents the correlation between percentage changes in real per capita consumption growth and in the corporate fraction.

\begin{tabular}{r|c}
\hline Calibration Input & Value \\
\hline Risk Aversion Coefficient & 5.00 \\
Subjective Discount Rate & 0.01 \\
Probability of a Jump & $1.00 \%$ \\
Jump in Consumption & $-10.00 \%$ \\
Jump in Dividends & $-90.00 \%$ \\
Consumption Growth & $2.34 \%$ \\
Consumption Volatility & $2.86 \%$ \\
Mean Corporate Fraction & $4.92 \%$ \\
Fraction Volatility & $27.03 \%$ \\
Fraction Autocorrelation & $5.80 \%$ \\
Correlation Coefficient & $63.20 \%$ \\
\hline
\end{tabular}




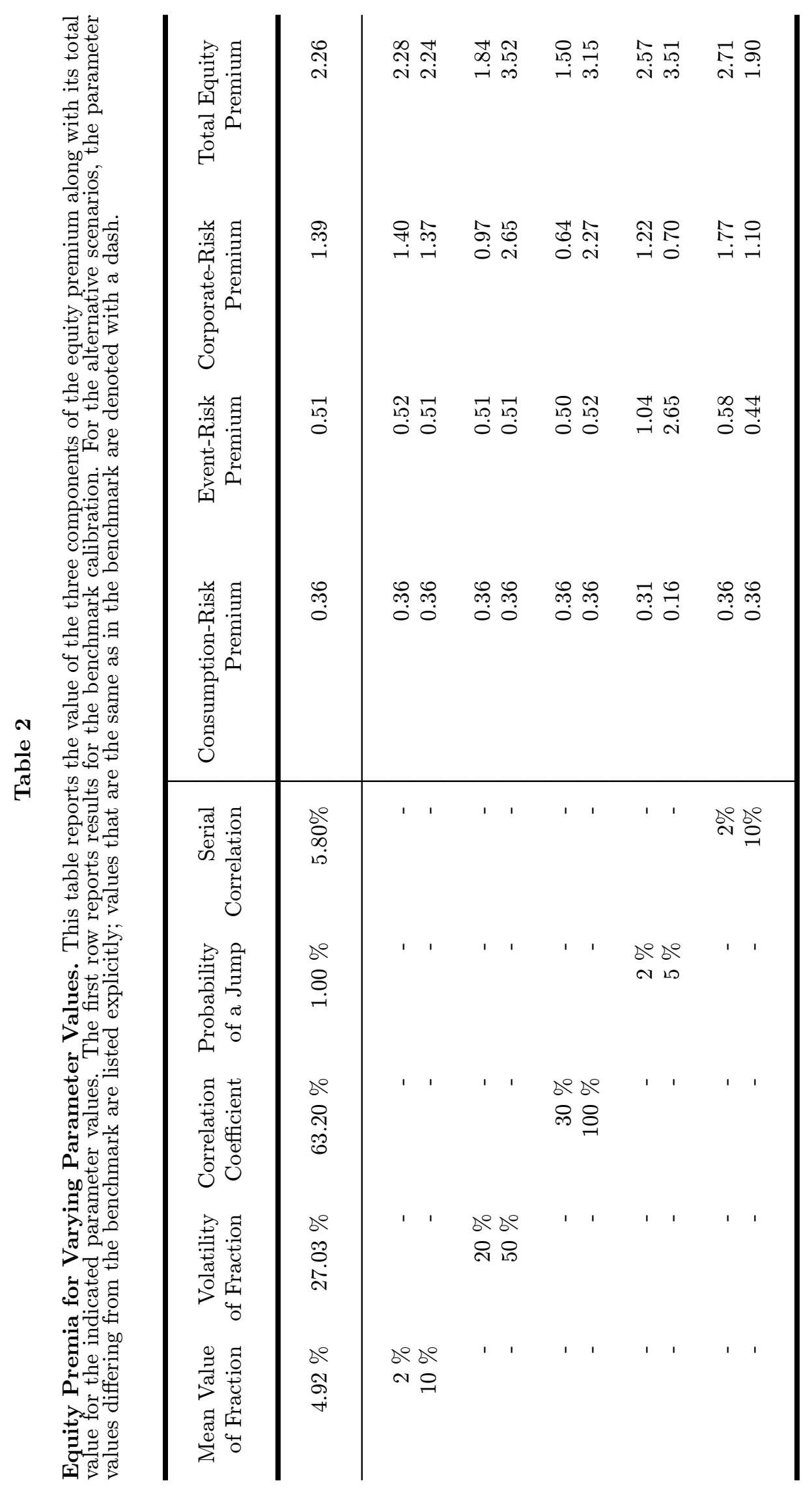




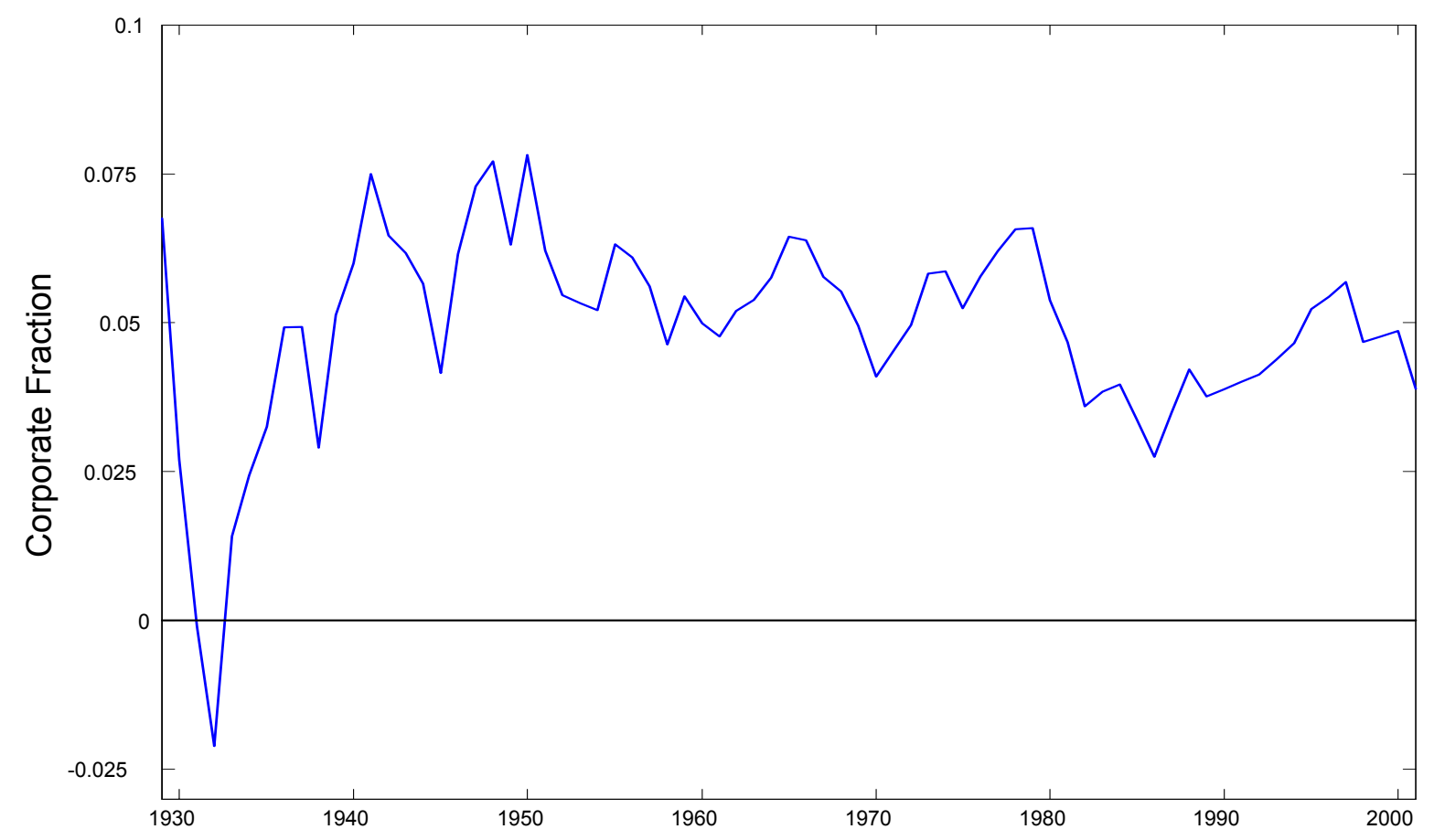

Figure 1: Time series plot of the corporate fraction from 1929 to 2001. The corporate fraction is the ratio of aggregate after-tax corporate earnings to aggregate consumption times the payout ratio. 


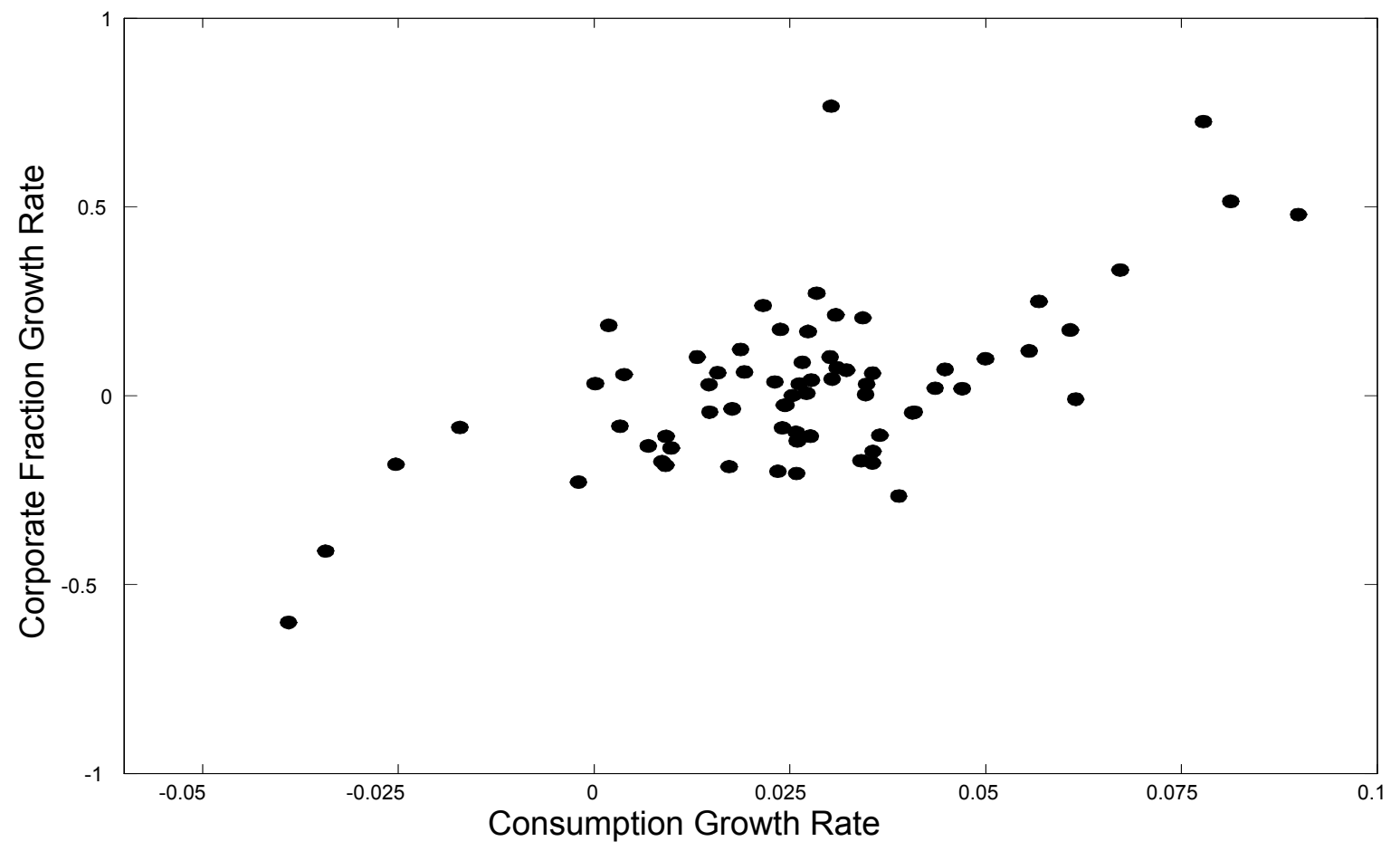

Figure 2: Plot of the corporate fraction growth rate against real consumption growth per capita from 1929 to 2001 (the years 1931-1932 are excluded). 